\title{
Determinants of adoption of improved maize varieties for male headed and female headed households in West Harerghe zone, Ethiopia
}

\author{
Yenealem Kassa ${ }^{1}$, , Ranjan S. Kakrippai ${ }^{1}$, Belaineh Legesse ${ }^{2}$ \\ ${ }^{1}$ Department of Rural Development and Agricultural Extension, Haramaya University, Ethiopia \\ ${ }^{2}$ Department of Agricultural Economics, Haramaya University, Ethiopia
}

\section{Email address:}

yenealemkassa@yahoo.co.uk(Yenealem K.), rskarippaib@gmail.com(R. S. Kakrippai), belaineh.legesse@yahoo.com(Belaineh L.)

\section{To cite this article:}

Yenealem Kassa, Ranjan S. Kakrippai, Belaineh Legesse. Determinants of Adoption of Improved Maize Varieties for Male Headed and Female Headed Households in West Harerghe Zone, Ethiopia. International Journal of Economic Behaviour and Organization. Vol. 1, No. 4, 2013, pp. 33-38. doi: 10.11648/j.ijebo.20130104.11

\begin{abstract}
This paper examined gender disparities in adoption of improved maize varieties between male headed and female headed households in Kuni district of West Harerghe zone, Ethipia. The study was based on cross-sectional data collected from a total of 148 respondents (115 were female headed and 33 were male-headed), using pre-tested structured interview schedule. The binary logit model results revealed that the adoption of improved maize variety is biased by gender, where FHH adopt the improved varieties less. Number of livestock units, extension services and cultivated land size had a significant and positive influence on the adoption decision of improved maize varieties, whereas age and distance to input market had a significant and negative influence on the adoption decision for MHH. Cultivated land size and distance to input market did not significantly affect the adoption of improved maize varieties for FHH, mainly due to less access of female heads to resources and services. Therefore, policy should address gender disparities in access to resources and extension services that exist because of socio-cultural and institutional factors limiting the adoption of technologies for FHH. In general, gender sensitive participatory technology development; improved literacy rate, efficient inputs delivery systems, and access to technical advice and market are essential to accelerate agricultural development through technology adoption.
\end{abstract}

Keywords: Gender Disparities, Adoption, Improved Maize Verities, Household Characteristics

\section{Introduction}

In addition to the main reproductive and domestic roles they are ought to play, rural women' productive role emanates from their involvement in direct crop production, livestock rearing, home management activities, and marketing of agricultural products and off-farm activities [1]. Generally, women contribute greatly to food security at household and at national levels. So, improving women producers' income implies a multidimensional contribution to the overall growth of the country [2].

Albeit, of the 1.2 billion people who live in conditions of absolute poverty in developing countries more than half are women. Especially, female-headed households are at the risk of living in poverty and disproportionately represented among the poorest of the poor, the uneducated and the first to suffer from drought and famine [3]. Despite, the important activities and responsibilities of women in different economic and natural resource management activities they have been overlooked and underrated, women's technological needs are not given enough attention and their knowledge was not used to assist in technology design and formulation of effective strategy [4].

Agricultural development programs and planning give inadequate attention to women farmers and their needs, and hence their farming activities take place on an ever shrinking resource base with extremely primitive technology and with severely stretched time resources [5]. Rural women especially female-headed households are rarely considered as clients for agricultural research and development programs or users of improved technology, and thus technical training and extension programs are almost exclusively targeted at men [6, 7, 4]. For example, development efforts of the last three decades in Ethiopia, in assisting small-scale farmers, through extension services 
that have targeted women farmers were associated with their traditionally accepted domestic roles, which are related with home management. The services were provided through the home economics section, which focused mostly on nutrition, sanitation, family planning, etc.

As indicated earlier, the nature and extent of men and women farmers' role in small scale farming vary from region to region, culture to culture, even from crop to crop. Accordingly, women face different problems and farming constraints and aspire technologies, which can address these differences. Given these state of affairs, being male or female in heading the household, in subsistence agriculture, matters a lot in terms of adoption decision [8]. As a result, an investigation of location specific situation regarding gender is essential to improve and adopt approaches and strategies appropriately. However, there is no empirical information to support the assumptions on adoption decision differentials between the two groups. Therefore, this study is conducted with the aim to produce empirical data that can provide a clear understanding of their circumstances and factors influencing male headed and female-headed households to adopt improved technologies in kuni district of West Harerghe Zone.

\section{Research Methodology}

\subsection{Description of the Study Area}

Kuni district is located in West Harerghe Zone of Oromiya Regional State "Fig 1". It is located at a distance of $362 \mathrm{~km}$ East of Addis Ababa, the capital city of the country. The area coverage of the district is 123,272 ha (CSA, 2003) and divided in to 38 PA's and two rural towns namely Bedessa and Karra. The capital town of the Zone is Chiro, which is $37 \mathrm{~km}$ from the capital of the district, Bedessa. The district is surrounded by Boke in the North East, Chiro in South East and East, East Hararghe in the East and Habro district in the West. The area is sub-divided in to three major climatic zones known to be Dega (consisting 4\% of the PA's of the district), Woinadega (31\%) and Kolla $(17 \%)$ and the average rainfall varies between 600 and $1200 \mathrm{~mm}$ per year. The topography is predominantly undulated with few hills and the climatic zones are set traditionally based on the differences in altitude variation ranging between 1100 up to 2200 meters above sea level (m.a.s.l). The mean monthly maximum temperature ranges from $22^{\circ} \mathrm{C}$ and $35^{\circ} \mathrm{C}$ with mean monthly average temperature $28.5^{\circ} \mathrm{C}$. Main economic activities in the area include both crop and livestock production. Some of the major crops grown in the area include maize, sorghum, teff and the rest being occupied by fruits and vegetables. In addition, majority the farmers use intercropping of cereals with T' chat (Catha edulis).

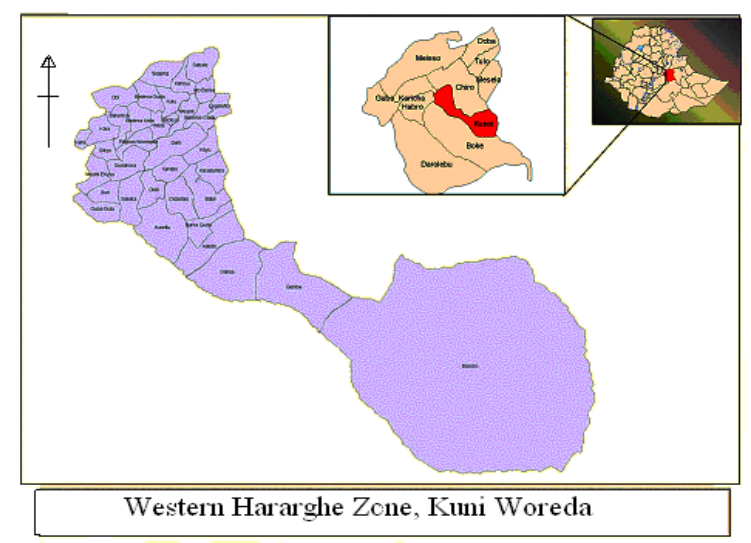

Figure 1. Geographical location of the study area (Kuni Woreda)

\subsection{Sampling Procedure}

A multi-stage stratified random sampling technique was followed to select PAs and households for the study. Based on this, considering the objective of the study and representativeness of the sample, the study focused on one agro-ecology (woinadega), which covers $68.9 \%$ of the total population of the district, and where the majority of maize producers are making their living. From the selected agro ecology, six PA's with more number of female-headed households were selected purposively (to increase the chance of sampling female headed households). To give equal chance in selection of study units from each concerned PA, probability proportional to size (PPS) was applied. Again proportional probability sampling technique was used to draw sampling units proportionally from each PA according to the number of adopters and non- adopters based on the list obtained from MOA office of the district. Consequently, the total sample size (160) was proportionally allocated to male and female-headed households (using proportional probability allocation), where 127 and 33 samples were selected from male-headed and female-headed households, respectively. Out of 127 male headed respondents, seven were unwilling and four were unavailable for the interview, and one was dropped because, was not a maize producer and all sampled FHH were interviewed. As a result, the data was collected from 148 (115 $\mathrm{MHH}$ and $33 \mathrm{FHH}$ ) respondents by well-trained enumerators using pre-tested structured interview schedule.

\subsection{Data Analysis}

The logistic regression model applied to assist in estimating the probability of adoption of improved maize varieties that can take one of the two values, adopt or do not adopt the technologies. According to [10], the functional form of the logit model is presented as follows:

$$
\begin{aligned}
& P_{i}=\mathrm{E}(Y i / X i)=\frac{1}{1+e^{-\left(\beta_{0}+\beta_{1} X_{i}\right)}} \\
& P_{i}=\mathrm{E}\left(\frac{\mathrm{Yi}}{\mathrm{Xi}}\right)=\frac{1}{1+e^{-Z_{i}}}
\end{aligned}
$$


Where $P_{i}$ is a probability of adopting a given technology for the $i^{\text {th }}$ farmer and ranges from 0 to $1 ; Z_{i}$ is a functional form of $n$ explanatory variables $(\mathrm{X})$ which is expressed as:

$$
\mathrm{Z}_{i}=\beta_{0}+\sum_{i=1}^{n} \beta_{i} \mathrm{X}_{i}, \text { where; } \mathrm{i}=1,2,3, \ldots \mathrm{n}
$$

Where; $\beta_{0}$ is the intercept and $\beta_{i}$ are the slope parameters in the model. The slope tells how the log-odds in favor of maize technology adoption change as independent variables change. If $P_{i}$ is the probability of adopting a given maize technology, then 1- $P_{i}$ indicates the probability of not adopting, which can be given as:

$$
1-\mathrm{Pi}=\frac{1}{1+e^{Z_{i}}}
$$

Dividing equation (1) by equation (3) and simplifying gives

$$
\frac{P_{i}}{1-P_{i}}=\frac{1+e^{Z_{i}}}{1+e^{-Z_{i}}}=e^{Z_{i}}
$$

Equation (4) indicates the odds ratio in favor of adopting improved maize technology. It is the ratio of the probability that a farmer will adopt a given technology to the probability he will not adopt. Lastly, the logit model is obtained by taking the natural logarithm of equation (4) as follows:

$$
\mathrm{Li}=\ln \left(\frac{P_{i}}{1-P_{i}}\right)=\beta_{0}+\beta_{1} X_{i}
$$

Where; $\mathrm{P}_{i}=$ the probability that $\mathrm{Y}=1$ (that the event occurs or probability of adoption); $1-\mathrm{P}_{i}=$ the probability that $\mathrm{Y}=0$ (that the adoption does not occur);

$\mathrm{L}=$ the natural $\log$ of the odds ratio or logit;

$\beta_{i}=$ the slope, measures the change in L (logit) for a unit change in explanatory variables $(\mathrm{X})$;

$\beta_{0}=$ the intercept. It is the value of the log odd ratio, $\frac{P_{i}}{1+P_{i}}$, when $\mathrm{X}$ or explanatory variable is zero.

Thus, if the stochastic disturbance term $(\mathrm{U} i)$ is taken into consideration the logit model becomes:

$$
\mathrm{Li}=\beta_{0}+\beta_{1} X_{i}+\mathrm{U}_{i}
$$

\section{Results and Discussion}

\subsection{Descriptive Statistics}

Of the total sampled households, 148 (115 MHH and 33 FHH), 56 (44.3\% of $\mathrm{MHH}$ and $15.2 \%$ of $\mathrm{FHH})$ farmers used improved maize varieties and $92(55.7 \%$ of $\mathrm{MHH}$ and
$84.8 \%$ of $\mathrm{FHH}$ ) farmers did not use during the main cropping season. The difference between these percentage figures between the two groups ( $\mathrm{MHH}$ and $\mathrm{FHH})$ is found to be significant at less than $1 \%$ level. This indicates that, male-headed households had adopted improved maize varieties at significantly higher levels than female headed households.

\subsection{Determinants of Adoption of Improved Maize Varieties}

Selected explanatory variables were used to estimate the logistic regression model to analyze the determinants of households' adoption behavior on maize variety. A logit model was fit to estimate the effects of the hypothesized explanatory variables on the probabilities of being adopter or not.

Before using logit model for hypothesized variables, it is important to test the problem of multicollinearity or association among the selected independent variables. For this case, the VIF is used to test the association between continuous explanatory variables.

VIF shows how the variance of an estimator is inflated by the presence of multicolinearity (Gujarati, 2003). According to Maddala [11], VIF can be defined as: $\operatorname{VIF}\left(\mathrm{x}_{\mathrm{i}}\right)$ $=\frac{1}{1-R_{i}^{2}}$

Where $R_{i}^{2}$ is the square of multiple correlation coefficients that results when one explanatory variable $\left(\mathrm{X}_{\mathrm{i}}\right)$ is regressed against all other explanatory variables. Once $\mathrm{R}^{2}$ values are obtained the VIF values can be computed using the formula. To avoid serious problem of multicollinearity, it is quite essential to exclude the variables with the VIF value exceeds 10 (this will happen if $\mathrm{R}_{\mathrm{i}}^{2}$ exceeds 0.90 i.e. highly correlated) from the logit analysis.

Similarly, there may also be interaction between two qualitative variables, which can lead to the problem of multi-co linearity or association. To detect this problem, coefficient of contingency were computed from the survey data, contingency coefficient is a chi-square based measure of association. A value of 0.75 or more indicates a stronger relationship. The contingency coefficient is computed as follows.

$$
C=\sqrt{\frac{\chi^{2}}{N+\chi^{2}}}
$$

Where, $\mathrm{C}=$ Coefficient of contingency

$\chi^{2}=$ Chi-square random variable and

$\mathrm{N}=$ total sample size.

The values of contingency ranges between 0 and 1, with zero indicating no association between the variables and values close to 1 indicating high degree of association. Based on the results of VIF $\left(\mathrm{x}_{\mathrm{i}}\right)$ of and contingency coefficients, serious problems of multicollinearity and degree of association were not observed among the continuous and dummy variables in case of both $\mathrm{MHH}$ and FHH, respectively. Therefore, nine explanatory variables 
(five continuous and four discrete) that are common for both MHH and FHH are included in the model.

To determine the best subset of explanatory variables, the logistic regression were estimated using the method of maximum likelihood estimation, which is available in statistical software program (SPSS version 12). The definition of variables and units of measurement that were used in the logit model are presented below. Prior expectations on the type of relationships between these variables and adoption of maize are provided in the parenthesis.

$\mathrm{X}_{1}$ TLUs (number of livestock owned) $(+)$

$\mathrm{X}_{2}$ RADIO (owned) $(+)$

$\mathrm{X}_{3}$ EXTCON (extension contact) $(+)$

$\mathrm{X}_{4}$ HHSIZE (household size) $(+)$

$\mathrm{X}_{5}$ EDUHEAD (education level of the household

head) $(+)$

$\mathrm{X}_{6}$ FRMSZ (area of farm in hectares) $(+)$

$\mathrm{X}_{7}$ DISTMKT (average distance from farm to market

in $\mathrm{km})(-)$

$\mathrm{X}_{8}$ AGE (age of the household head) (-)

$\mathrm{X}_{9}$ OFFACT (off farm activities of the house hold head) $(+)$

Table 1. Parameter estimates of a logistic model for factors affecting adoption of improved maize varieties.

\begin{tabular}{|c|c|c|c|c|}
\hline $\begin{array}{l}\text { Household } \\
\text { characteristics }\end{array}$ & $\begin{array}{l}\text { MHH } \\
\text { Parameter } \\
\text { estimate } \\
(\beta)\end{array}$ & $\begin{array}{l}\text { Wald } \\
\text { Statistics }\end{array}$ & $\begin{array}{l}\text { FHH } \\
\text { Paramete } \\
\text { r estimate } \\
(\beta)\end{array}$ & $\begin{array}{l}\text { Wald } \\
\text { Statisti } \\
\text { cs }\end{array}$ \\
\hline Constant & -3.773 & 3.604 & -6.618 & 0.425 \\
\hline House hold size & 0.066 & 0.182 & -0.013 & 0.001 \\
\hline Radio & 0.679 & 0.991 & 0.919 & 0.779 \\
\hline Livestock & $0.882^{* * *}$ & 10.027 & $1.724^{* *}$ & 3.888 \\
\hline Extension contact & $3.275^{* * *}$ & 11.977 & $4.112^{*}$ & 2.995 \\
\hline Education & 0.080 & 0.099 & 0.117 & 0.004 \\
\hline Farm size & $1.625^{* *}$ & 6.487 & 2.414 & 0.607 \\
\hline Distance to market & $-0.573^{* *}$ & 5.543 & -0.359 & 0.221 \\
\hline Off farm & 0.692 & 0.707 & -2.149 & 0.428 \\
\hline Age & $-0.102^{* * *}$ & 8.114 & -0.030 & 0.056 \\
\hline$\chi^{2}$ & $87.604^{* * *}$ & & $18.53^{* *}$ & \\
\hline-2 log likelihood & 70.347 & & 9.542 & \\
\hline $\begin{array}{l}\text { Correct predicted } \\
\text { of all samples }(\%)\end{array}$ & 87 & & 96.4 & \\
\hline $\begin{array}{l}\text { Correct predicted } \\
\text { non adopters }(\%)\end{array}$ & 89.1 & & 80.0 & \\
\hline $\begin{array}{l}\text { Correct predicted } \\
\text { of adopters }(\%)\end{array}$ & 84.3 & & 93.9 & \\
\hline
\end{tabular}

Note: ${ }^{*}=$ sig. at $\mathrm{P}<0.1 ;{ }^{* *}=$ at $\mathrm{P}<0.05$; and ${ }^{* * *} \mathrm{P}=$ sig. at $\mathrm{P}<0.001$

The logit model results used to study factors influencing the adoption decision of improved maize variety for $\mathrm{MHH}$ and $\mathrm{FHH}$ respectively are shown in Table 1 . The various goodness of fit measures depicted in this Table revealed that the model fits to the data well. The $\chi^{2}$ indicates that the parameters are significantly different from zero at less than $1 \%$ and less than $5 \%$ probability level for $\mathrm{MHH}$ and FHH, respectively. The model explained about $87 \%$ and $96.4 \%$ of the total variation in the sample for use of improved maize for $\mathrm{MHH}$ and $\mathrm{FHH}$, respectively. Correctly predicted figures for adopters were about $84.3 \%$ and $93.9 \%$; while correctly predicted sample size for non-adopters were $89.1 \%$ and $80 \%$ for $\mathrm{MHH}$ and $\mathrm{FHH}$, respectively.

The logistic regression model analysis result indicates that cultivated farm size (FRMSZ) exerted positive influence $(\mathrm{P}<0.05)$ on the adoption of improved maize varieties for $\mathrm{MHH}$. If farm size can be increased by unitary value, the odds in favour of adopting improved maize varieties would increase by a factor of 5.078 for $\mathrm{MHH}$. This result implies that $\mathrm{MHH}$ with large farm size are more likely to adopt improved maize varieties than those $\mathrm{FHH}$ who have small land size. But, the separate logit model built for FHH has shown that there is no significant influence on adoption decision of FHH. In fact, in the study area, FHH have significantly less area of cultivated land compared to male-headed households $(\mathrm{t}=-5.671, \mathrm{P}=0.001)$.

The model result also indicated that number of tropical livestock units (TLUs) affects positively and significantly the probability of adopting improved maize varieties at $(\mathrm{P}<0.01)$ and $(\mathrm{P}<0.05)$ for $\mathrm{MHH}$ and $\mathrm{FHH}$, respectively. This result shows that those farmers with large number of tropical livestock units are more likely to adopt improved maize varieties than those who own small number of TLU. Cattle can be a source of income that can be used to buy improved maize variety. It enhances the shock absorbing capacity of the households in case of crop failure. The result hints that on increase in TLU by one unit would mean that, the odds in favour of adopting improved maize varieties could increase by a factor of 2.415 and 5.448 for $\mathrm{MHH}$ and $\mathrm{FHH}$, respectively. In addition, female-headed households are less likely to own livestock but those female-headed households with relatively more land size have more number of livestock.

Extension contact (EXTCON) had also a positive and significant influence on the probability of adoption of improved maize varieties at less than $1 \%$ and $10 \%$ significant level for $\mathrm{MHH}$ and $\mathrm{FHH}$, respectively. The result indicates that, women and men are faced by differential access to new technologies. However, farmers who had extension visit have higher probabilities towards adoption than those with less exposure. The odds in favour of adopting improved maize varieties increased by a factor of 22 and 55.076 for $\mathrm{MHH}$ and $\mathrm{FHH}$, respectively that had access to extension services. However, in the study area, $\mathrm{MHH}$ received more visits by extension agents compared to FHH.

Age has negative and significant influence $(p<0.01)$ on the probability of adoption for $\mathrm{MHH}$. The negative association suggests that the likelihood of adopting improved maize varieties declines as the age of the 
household head increases. The odds in favor of adopting improved maize variety decreases by a factor of 0.903 as the age of the household head increases by 1year for MHH. The possible explanation for this result is that $\mathrm{FHH}$ do not benefit much from extension services.

Distance to the nearest input market (DISTNCE) is also another factor, which has a negative and significant influence on the probability of adoption of improved maize varieties at less than 5\% significant level for MHH. The negative association suggests that the likelihood of adopting improved maize varieties declines as the distance from market center increases. In other words, if the distance between MHH's homestead and the market area is longer, the farmers will be discouraged from adopting improved maize varieties. The result mirrored that odds in favour of adopting improved maize variety decreases by a factor of 0.564 as the market distance increases by $1 \mathrm{~km}$. This finding agrees with a priori expectation in that farmers who live far away from market place have limited access to input market and tend to be reluctant to take up new technologies as compared to those farmers who live near to input market places. However, it is found that there is negative but insignificant influence on adoption decision of FHH, because as stated earlier FHH benefit less from these extension services, regardless of distance to input markets.

\section{Conclusion and Recommendations}

Agricultural scientists and researchers have developed number of technologies that can increase the productivity of farmers, but farmers often did not adopt these technologies, because the technologies did not meet their needs. Moreover, needs and priorities of women farmers especially FHH have been rarely considered in the past in the research and development of agricultural technologies. Thus, there is a need to reorient the researchers and development agents in such a way that they could accommodate the needs and requirements of males and females consistently. This will help to create gender awareness among the researchers and extension workers to reorganize the roles and needs of men and women households and give adequate attention to their needs. The following recommendations are forwarded based on the findings of the study.

Results obtained in the present study have indicated that the adoption of improved maize varieties is biased by gender, where female-headed households adopt technologies less. This was mainly due to significantly less access of female-headed households to formal education, land, and had less access to extension services and information on improved maize variety. Thus, there is an urgent need for policy makers to address gender disparities in access to extension services, formal education and their access to land that exist because of socio-cultural and institutional factors limiting the adoption of technologies by female headed households. One way of improving the situation could be through provision of extension services and information and special education programs as well as giving more education opportunities for children from such households.

Since livestock holding was one of the significant factors influencing adoption of improved maze variety for both $\mathrm{MHH}$ and $\mathrm{FHH}$, intervention to improve livestock sector should be encouraged through empowering farmers to own livestock through provision of livestock credit. Furthermore, development of improved livestock feed, and veterinary service should be encouraged.

It was found that farm size significantly affects adoption decision of improved maize varieties by $\mathrm{MHH}$. The result shows that the new maize variety is more likely to be adopted by male farmers with large farms. This implies the need of research, extension, and planning agencies to be sensitive to the needs of smaller farmers through developing and disseminating technologies and strategies that are relevant to their needs.

The results of the study also revealed that age of male household head influences the adoption of improved maize negatively and significantly for $\mathrm{MHH}$. Younger $\mathrm{MHH}$ are more likely to adopt a new technology such as use of improved maize. Hence, introduction of new agricultural technology in the area may be successful if it focuses more on younger farmers.

For farmers to adopt improved agricultural technologies they need to get intensified agricultural extension services in the form of training and field support individually, in group and mass methods through compatible communication and extension messages transferring methods. Moreover, agricultural training is not gender sensitive and participation of female farmers in agricultural technologies is very minimal. Policy makers and government officials need to assure farmers' accessibility to proper extension services for guaranteed agricultural and rural development of the country. Extension services should play a greater role in organizing women farmers to become full beneficiaries of the farmers associations. This will help to group farmers according to their social and economic status, level of achievements and aspiration. This in turn will facilitate the identification of specific needs and address the primary concern of women and their demands for labour-time using a multi dimensional participatory approach. Thus, systematic arrangements of farmer training should be implemented in order to acquaint farmers with different agricultural technologies. Similarly, timely provision of agricultural inputs and credit, improving infrastructure of the rural area, and conducting follow-up supervision would improve farmers' access to information and agricultural inputs.

The traditional home economics extension program that targeted rural women made a substantial contribution though it was focusing on the domestic domain only. It will be of great importance if this approach could be reorganized and structured in a new methodology by incorporating the productive dimension of the gender aspect. Moreover, agricultural interventions should 
incorporate labour saving technologies to improve their productivity by reducing the workload and relieve women from the routine domestic activities.

\section{References}

[1] Lenesil Asfaw, 1996. Gender Training Workshop Handout and Reader. Integrated Forest Management Project. Dodola, Ethiopia. 71p.

[2] Yeshi Chiche, 2002.Comparative Analysis of Gender Related Farm Households in the Arsi- Negele Farming Zone, Ethiopia, 70p.

[3] World Bank, 2000b.Voices of the Poor: Can Any One Hear Us? Deepa Narayan, Raj Pate Kai Schafft, Anne Rademacher and Sarah Koch-Schulte (eds). Washington, DC $101 \mathrm{p}$

[4] Addis Tiruneh, 2000. The Missing Link Between Micro and Macro Level Gender Dis-aggregated Economic Data in Economic Policy Formulation and Planning in Ethiopia. WID/Department of Economics, Unpublished Paper, Addis Ababa University, Ethiopia. 62p.
[5] United Nations Educational, Scientific and Cultural Organization (UNESCO), 1985. Women in a world perspective, France.23p.

[6] Food and agricultural organization (FAO), 1998. Rural Women and Food Security. Current Situation and Perspectives, United Nations. 137 pp.

[7] Tiruwork Tizazu. 1998. Access to Resources and Productivity of Female-headed Households: The Case of East Gojjam and North Shoa, MA Thesis, Addis Ababa University, Ethiopia.

[8] Legesse Dadi, 1992. Analysis of Factors Influencing Adoption and the Impact of Wheat and Maize Technologies in Aris Nagele, Ethiopia. An M.Sc. Thesis Presented to the School of Graduate Studies of Alemaya University. 127p.

[9] Central Statistical Authority (CSA). (2003), "Ethiopia Statistical Abstract 2000", Ethiopia.

[10] Gujarati, D.N. (2003), "Basic Econometrics", 4 $4^{\text {th }}$ Edition., New York, McGraw-Hill.

[11] Maddala, G.S, 1983. Limited Dependent and Qualitative Variables in Econometrics, Cambridge University Press, Cambridge. $401 \mathrm{pp}$. 